\title{
School Turnaround: A Rural Reflection of Reform on the Reservation and
}

\author{
Lessons for Implementation
}

\author{
Ian M. Mette \\ University of Maine \\ Jason Stanoch \\ University of Missouri
}

\begin{abstract}
Rural communities traditionally enjoy an intimate relationship between stakeholders and the local school system. While preliminary research exists to suggest rural school turnaround might be more likely to occur when a strong communal connection exists (Mette, 2014), little is known about rural school turnaround efforts serving predominantly Native American students. This article reports findings of a School Improvement Grants (SIG) funded effort to digitize curriculum and deliver instruction through the use of tablets in Yellow Pine, a school district on a Native American reservation in a rural, Upper Midwestern state. Data were collected through interviews with school and district leaders, as well as through teacher focus groups. Findings highlight the failure to engage a historically disenfranchised community from the beginning of the improvement process, particularly the lack of involvement of students, parents, and teachers, which in turn led to little impact on student achievement.
\end{abstract}

Keywords: school improvement grants, school turnaround, Native American education, rural reform efforts, one-to-one initiatives

Starting in 2009, the American federal government has funded over $\$ 3.5$ billion in School Improvement Grants (SIG) as reform initiatives (US DOE, 2010). These efforts provide much needed resources and funding to traditionally underperforming schools, and specifically target technical change that might lead to greater student outcomes. That being said, there remains a great debate about the impact and effectiveness of high stakes school reform policy targeting low achieving schools (Duke, 2012; Gorski \& Zenkov, 2014; Renée \& Trujillo, 2014; Stein, Stein, \& Stein, 2013), and whether SIG funded reform efforts provide enough support and capacity building to failing schools to help target more strategic use of resources to improve student achievement (Education Resource Strategies, 2012). More specifically, the investigation regarding the balance of technical and cultural improvement efforts should be studied further when trying to improve school performance in a rapid manner (Mette, 2013). As a result, there is a need to understand not just what school reform efforts work, but just as importantly, how a school system involved in implementing SIG funded efforts translates theory into practice (Mette, 2014). By studying how school districts can best plan for and implement change in their lowest performing schools, researchers can better identify why some school turnaround efforts are able to address issues of social inequities, cultural issues, and technical aspects of improvement while simultaneously increasing academic outcomes.

To improve academic success, the goal of all SIG funded efforts, many educators and policy makers suggest the integration of technology to increase student engagement, however there remain questions about how rural educators integrate technology into their classrooms and the impact this has on rural student achievement (Howley, Wood, \& Hough, 2011). More specifically, educational leaders who work in Native American school systems are challenged with technology integration due to a variety of factors, including remote location, high poverty levels, and cultural degeneration (Richardson \& McLeod, 2011). Historically, White school systems provided to Native American students have systematically attempted to eliminate identity, as well as a sense of culture and community (Noel, 2002), and this continues through national standards-based reform efforts that struggle to find value in culturallybased instruction (Beaulieu, 2011). Often times, life on a Native American reservation reflects a lack of economic opportunities, high levels of poverty, and low levels of education - Native Americans are among the least educated ethnic groups in America, which impacts long-term health and life expectancy (Locke, 2004). Thus there is the need for community 
development activities that will strengthen cultural celebrations, increase employment opportunities on reservations, improve access to college education, and build capacity collaboratively with tribal members to improve their community (Huffman, 2011). However, education state systems often struggle to help build capacity within low-performing schools that can help address these communitybuilding activities. That being said, school systems that support Native American reservation communities often have a daunting task of improving access to technology and providing education that will not only lead to greater student achievement, but also provide culturally proficient instruction, as well as valuable technology-based skills, in the hope of increasing education and community development opportunities.

The purpose of this qualitative study was to investigate how and to what extent SIG funded efforts - specifically the requirements of the transformation model - promotes greater community, teacher, and student engagement through increased technology integration for a highly disenfranchised Native American community on a reservation in a rural, Upper Midwest State. The State Department of Education (SDOE) identifies the school district, Yellow Pine, to be continually in the lowest 5\% with regard to state standardized test scores. Additionally, the district has seen an influx of allocated resources for the last several years; these resources most recently have come in the form of SIG funding and have targeted a reform effort to implement a digitized curriculum. In digitizing the curriculum, the hope of the Yellow Pine District was to increase engagement of students through the use of technology.

In order to analyze how policy implementation might lead to increased student achievement and overall academic engagement, the researchers sought to understand how local district leaders supported and managed the digitized curriculum effort at the school level. In an attempt to assess the impact of transformation efforts on Native American school systems, this study reports on the perspectives of participants within the Yellow Pine District as they relate to student achievement, educational leadership, and school improvement. Additionally, the researchers sought to better understand the relationship between policy in theory and policy in practice, but also what SIG funded policy tells educators about the impact it has on traditionally disenfranchised communities, specifically for Native American reservations. As a result of this study, the researchers intend to add to school reform literature, not only addressing how SIG policy impacts Native American school systems, but also informing the type of policy revision that are needed to better support community improvement with traditionally disenfranchised groups of rural students.

\section{Literature Review}

Through most of the $20^{\text {th }}$ century, rural schools played an integral, almost exclusive, role of instilling values, sharing knowledge, ensuring local economic health, and serving as the hub of community events for the populations they served; and in doing so they were also largely free of economic restrictions and current accountability measures (Howley, Howley, Hendrickson, Belcher, \& Howley, 2012). As rural schools have progressed into the $21^{\text {st }}$ century, educational leaders have experienced increased pressure to improve student achievement of traditionally disadvantaged rural students in response to accountability measures (Forner, Bierlein-Palmer, Reeves, 2012). SIG funded efforts play a large role in this process, providing often much needed resources in exchange for instructional reform that more closely scrutinizes teacher and administrator effectiveness. Increasingly, rural schools have targeted improvement efforts to integrate technology into classrooms as a means to improve engagement of students in the hope of providing quality learning activities that might translate into greater student achievement (Howley et al., 2011). In order for rural school systems to engage in instructional leadership, particularly around one-to-one initiatives, it is crucial to work closely with stakeholder groups to help translate vision into action (Wood, Finch, \& Mirecki, 2013).

While providing technology leadership to schools that support predominately Native American populations is similar to the leadership required in other rural schools, technology leadership in Native American schools face additional challenges from Bureau of Indian Education (BIE) regulations, piecemealed professional development, and cultural considerations (Richardson \& McLeod, 2011). Throughout different parts of the United States, pockets of Native American schools have used technology to teach and resuscitate local tribal languages through stories, pictures, art, and other forms of visual representations that attempt to enrich oral histories (Noori, 2011). Additionally, while all tribal heritage is different, it is important to understand and remember that Native American identity, culture, and values are inextricably linked to Native American education (Charley, 2013), and as such, technology integration might not be a simple task to implement.

\section{Overview of School Improvement Grants}


Since 2009, to receive SIG funding, schools must commit to take part in implementing one of four models, namely 1) turnaround, 2) transformation, 3) closure, and 4) restart (US DOE, 2013).

Transformation and turnaround are two SIG models that make up 93.9\% of the reform efforts chosen in schools (US DOE, 2011). However, as seen in Figure 1.1, early data suggests a large distinction in the models adapted based on population density, seemingly providing greater flexibility to communities to choose the turnaround model classified as suburban and urban (26.5\% and $25.5 \%$, respectively) and being more restrictive to communities to choose the turnaround model classified as town or rural (2.1\% and $8.3 \%$, respectively) (US DOE, 2011). Previous studies on SIG funded efforts in rural areas suggests this could be due to the inability of a rural school to replace $50 \%$ of the staff, which is more likely to be possible in urban area where there are greater numbers of qualified teachers to recruit (Mette, 2014; Rosenberg, Christianson, \& Angus, 2015). As a result, 94.1\% of schools classified as rural or town chose the transformation model through the 2009-2011 SIG application cycles. An increasing amount of literature suggests federal policy imposes a one-size fits all approach to reform, negatively influencing rural schools (Johnson \& Howley, 2015). However, starting in the 2015-2016 school year, SIG efforts are to include rural school flexibility to alter one element of the turnaround or transformation model (Redding, Dunn, \& McCauley, 2015), likely making it more feasible for rural schools to select the turnaround model.

Schools with SIG funding are significantly more likely than schools without SIG funding to attempt implementation of comprehensive instructional reform strategies, seek to improve teacher and principal effectiveness, increase learning time and support the concept of community-oriented schools, and have greater operational flexibility in how they address low-student achievement (JamesBurdumy, 2015). Based on a 2013 survey in which 480 administrators of schools receiving SIG funding participated, over $96 \%$ of SIG funded schools employed three of the most common improvement efforts to increase low student achievement, specifically 1) using data to provide differentiated instruction, 2) increasing technology or computeraided instruction, and 3) increasing collaborative practices to drive professional development (Herrmann, Dragoset, \& James-Burdumy, 2014). However, despite substantial efforts to turnaround low-performing schools through the financial support of SIG and Race to the Top grants (Tanenbaum et al., 2015), as well as technical support and increase accountability efforts (Scott \& McMurrer, 2015), states continue to struggle to build capacity at the local school level to support these cultural improvement efforts. Additionally, rural areas could be well poised to capitalize on local conditions to promote dramatic SIG funded efforts and build sustainable improvement capacity within their communities (Yatsko, Lake, Bowen, \& Nelson, 2015).

Figure 1.1 SIG Awards by Model as of 2011

SIG Awards By Model as of 2011

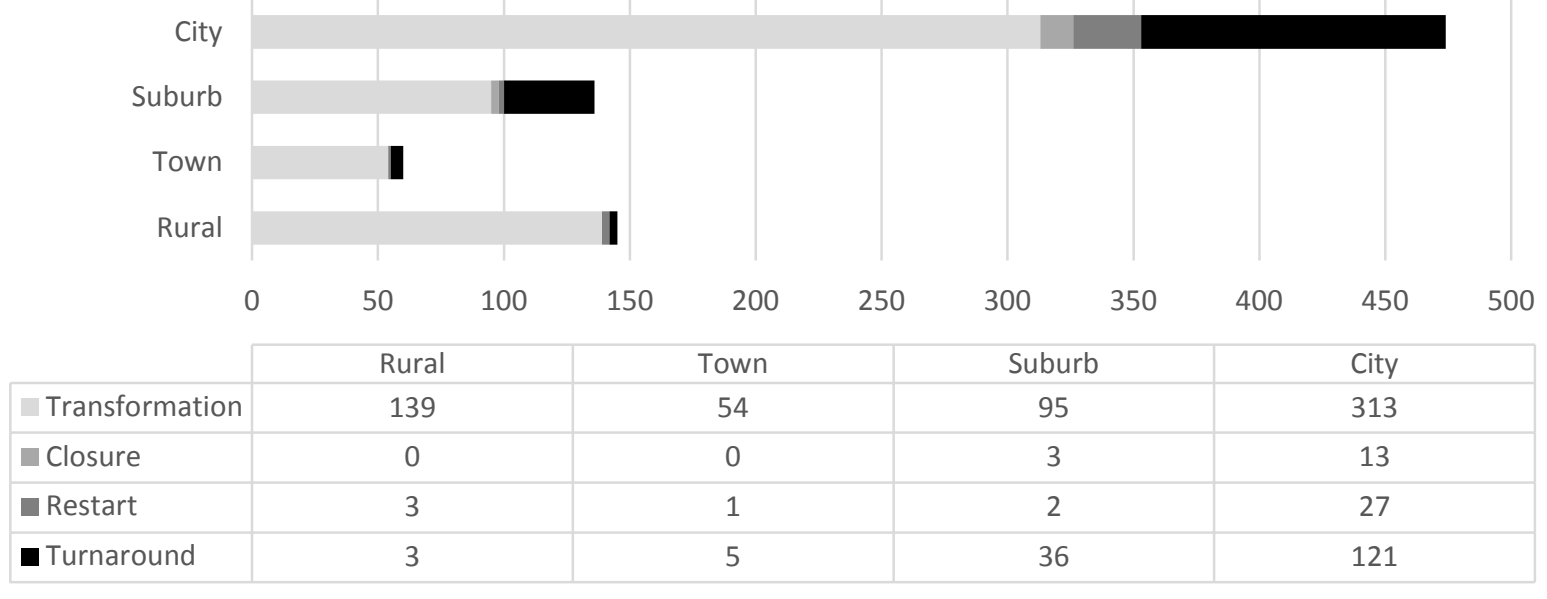

Figure 1.1. Adapted from An Overview of School Turnaround. (US DOE, 2011). 


\section{Technology Integration and One-to-One Programs}

One-to-one programs, which are intended to provide equitable access to all students by eliminating technological barriers, often differ greatly in their ability to meet the needs of different student groups and provide meaning instruction that leads to greater levels of engagement (Warschauer, Zheng, Niiya, Cotton, \& Farkas, 2014). Proponents of oneto-one programs suggest the increased use of technology can lead to improved student achievement, differentiation of instruction, increased access to resources, greater attendance, and fewer discipline concerns (Mortensen, 2011; Rosen \& Beck-Hill, 2012). Additionally, some educators believe the use of one-to-one tablets will reduce (and even eliminate) the use of textbooks in classrooms, with the focus of these initiatives providing increased access to online materials that can foster more collaborative, constructivist-based projects (Maninger \& Holder, 2009).

However, while significant resources have been provided to launch one-to-one programs, less is known about how to successfully and sustainably implement these programs, including preparation of preservice teachers (Donovan \& Green, 2010), as well as initial training for practitioners, support that is imbedded through ongoing professional development, and the empowerment of students to take custody of the technology being used (Howard \& Rennie, 2013). While little longitudinal research exists, Blackley and Walker (2015) suggest in one study that a one-to-one program that has existed for over seven year struggled to fully integrate technology in a manner that meaningfully impacted pedagogical practices. As a result, in order for oneto-one programs to be successfully implemented, schools must support change based on social capital of students and teachers within the school, as well as parental involvement (Li, 2010). These improvement efforts must not only focus on the technical aspects of school reform, but also on the cultural.

\section{Rural Technology Leadership and Within a Native American Context}

Rural school leaders must be able to function as change agents of their school buildings, promoting curricular alignment, continually targeting instructional improvement, and assisting in the integration of technology to promote engaging learning (Doolittle \& Browne, 2011). Increasingly, there are burdensome and complex demands put on rural school systems as American policy makers implement school accountability and reform efforts
(Preston, Jakubiec, \& Kooymans, 2013). Rural school systems often struggle to maintain both teachers and administrators (Rosenberg, Christianson, Angus, \& Rosenthal, 2014; Wood et al., 2013), particularly in schools that are traditionally underperforming (Preston et al., 2013). Thus, the focus on technology integration in the classroom, specifically how the use of technology can translate into better instructional practices for teachers and increased achievement for students (Dexter, 2011), highlights the importance for principals to not only be instructional leaders, but be leaders of technology. However, little research exists on the skills and knowledge needed for rural instructional leaders to support technology-driven reform efforts that lead to the expected increase in student achievement (McLeod \& Richardson, 2011).

As there exists a lack of educational technology integration in most educational leadership programs (Schrum, Galizio, \& Ledesma, 2011), it is likely that most rural leaders will need to develop their own understanding of contextual technology application. Anthony (2012) posits that in order for technology integration to successfully impact student achievement, technology leadership must be able to not only impact and influence individual practices, but also assess institutional protocols and policies to ensure linkages exist between the proposed technology improvement effort and the ability to implement the technology in practice. Moreover, there is a need to acknowledge the chance to address issues of social justice through technology integration (McLeod, Bathon, \& Richardson, 2011), not through simply putting technology in the hands of students from low SES backgrounds or traditionally disenfranchised groups, but rather using technology to empower students to investigate issues of inequity.

Providing technology leadership in a rural Native American school setting requires even more expertise, specifically how school leaders can ensure the technology being applied is relevant to meet the cultural traditions and needs of the community (Richardson \& McLeod, 2011). In the most philosophical sense of reform, specifically in a rural, Native American reservation context, students and educators should challenge White, Euroamerican education systems and openly question what type of education is considered 'right' or 'correct', particularly as it relates to Native American culture, identity, and history (Shumaker, 2007). Allowing students in Native American schools to explore identity and provide critical analysis of a history of "persecution and marginalization at the hands of the (White) majority society" is an important aspect to consider, particularly the use of technology as a tool of empowerment to better understand tribal cultures 
and historical identities (Charley, 2013, p. 1). Thus, Native American education systems can use technology as a source of empowerment to reform how education is delivered for Native American students through pedagogically sound practices and strengthen cultural identities, challenging negative stereotypes and narratives about Native American education, and attempting to break free from an educational institution that reinforces Euroamerican principles, (Fletcher, 2008; Tharp, 2006).

\section{Context of the Study}

Yellow Pine Indian Reservation ${ }^{1}$ is considered a limited sovereign nation in which the tribe cannot issue currency, maintain a guarded border, or have a standing army (Treuer, 2012). Natural beauty and wilderness surround the community, with little to no development impacting fishing or hunting opportunities. Based on the governing practices of the Yellow Pine Indian Reservation, to be allowed to live in an allotted home, receive tribal services, or operate a business, one must be an enrolled member of the tribe. The criterion for tribal enrollment is based within the ideals of the traditional official tribal affiliation established during the 1800s, in which a tribal member must demonstrate their lineage in order for it to be applied to a formula for calculating blood quantum. If one can prove a minimum $25 \%$ blood quantum, he can be enrolled as a member. This has bearing on the study because this has a direct impact on the demographics of the reservation, with $100 \%$ of the students of Yellow Pine identifying as Native American. The presence of a blood quantum system highlights one of the many archaic remnants the U.S. government used to study and categorize Native peoples. This system was later used not only to determine membership, but also to what extent restrictive laws applied to individuals and the rights to benefits such as land settlement payments.

Yellow Pine is a community defined by extreme levels of poverty, high unemployment, strong presence of gang affiliation, and high levels of suicide and homicide. Of the students attending the Yellow Pine School District, 90\% qualify for free and reduced lunch, and the unemployment rate on the Yellow Pine reservation is estimated at 60\%. During the time data was collected for this study, multiple suicides shook the reservation and a federal investigation into the death of a teenage boy shot execution style in the back of the head led to no arrests. Many families of Yellow Pine have lived within the same subset of the community since their

\footnotetext{
${ }^{1}$ Yellow Pine is a pseudonym to protect the identity
} of the participating school district. ancestral clans settled there, and the geographical separation has resulted in significant cultural difference between the communities. When presented with the choice of where to live, people on the Yellow Pine Reservation rarely move due to the economic and social reasons listed above.

In the context of this study, economic development, or lack thereof, and familial ties, impact the perceived value of public education, particularly among families that need high school students to work in order to provide income for the family. One must also take into account the long history of low graduation rates and high suspension and expulsion rates of Native American students (Freeman \& Fox, 2005), which again can be a byproduct of economic conditions. During the 20132014 school year, less than $60 \%$ of students graduated from Yellow Pine High School, districtwide 742 state recorded referrals were assigned to 1,491 students (a suspension rate of $49.7 \%$ ), and on the high school end-of-course exams for math, reading, and science, less than $9 \%$ of students scored proficient or higher. Additionally, the five superintendents who have held the Yellow Pine position over the last six years highlights that while teacher turnover is relatively moderate, administrative turnover is very high. Moreover, there is an extreme lack of diversity among teachers. For example, at Yellow Pine High School, 3 out of 31 teachers identify as Native American, and the remaining $90.3 \%$ of the staff identify as White. Given this context, the intent of this study was to examine if SIG funded efforts that focused on implementing a one-to-one tablet initiative within a Native American school system could engage all stakeholders of the Yellow Pine community to promote increased student engagement and achievement, as well as support greater inclusion of indigenous knowledge and cultural values.

\section{Method}

This study investigated the leadership building principals and district administrators in a SIG funded, rural school district provided. The Yellow Pine School District was selected to investigate how the Yellow Pine district and building administrators determined the need for, planned, and implemented the SIG funded one-to-one tablet initiative to digitize curriculum, and thus rapidly improve achievement. The following question guided the study of how district and building leadership of the Yellow Pine School District attempted to approach to change during the school turnaround process: How and to what extent does the SIG funded effort promote greater community, teacher, and student engagement 
through increased technology integration for a highly disenfranchised Native American community on a reservation in a rural, Upper Midwest State?

Responsive interviewing was employed to fully understand the perspectives and narratives of those attempting to implement the school improvement effort in Yellow Pine, allowing the researchers to analyze various interpretations and perceptions of participants gathered from in-depth interviews (Rubin \& Rubin, 2012).

A case study approach was used in this qualitative study to understand the process and actions of participants within a bounded system over the course of time (Creswell, 2013), specifically those involved with the Yellow Pine school turnaround initiative and how the process of school improvement evolved over the course of a school year. The researchers used a purposeful sampling approach to identify administrators who might be willing to take part in the study, and teacher focus groups were identified at both the elementary and secondary level as well to ensure a thorough understanding of the school improvement effort. In all, nine administrators were interviewed, including four building principals, four district leaders, and one state-appointed turnaround officer, in both the fall and spring of the same school year. Both the elementary and secondary teacher focus groups were interviewed twice as well, once in the fall and once in the spring. Researchers also gathered additional data, such a relevant district communications, public documents, and researcher fieldnotes to triangulate data (Miles, Huberman, \& Saldaña, 2014).

Once participants were identified and agreed to participation, interviews were conducted. Each individual participant chose the interview time and location, and a semi-structured interview protocol was used to provide a conversational approach to data collection. In doing so, the participants were able to influence the direction of the study which simultaneously addressed the research questions. In all cases, with the permission of each participant, a voice recorder was used to preserve the content of the conversation, and subsequently each interview was transcribed verbatim. An open coding process was used to identify major categories that emerged from the interviews (Creswell, 2013), from which axial coding was used to organize data into subthemes and dimensions (Saldaña, 2013). Through analyzing the themes that emerged from data collected, the study focused on how Yellow Pine district leadership engaged the community in the school turnaround process and provided ongoing support to incorporate the digitized curriculum effort to help address the school improvement effort.

\section{Findings}

A common theme that emerged from the interviews highlights the inability of the Yellow Pine School District leadership to engage stakeholders of the school district in the school improvement process, including parents, teachers, and students. While the technical aspects of technology implementation and integration were addressed, there was a lack of engagement with the Yellow Pine community that prevented cultural changes from being addressed, and ultimately student achievement was not impacted. The SIG funded reform effort provided resources and incentives for the school district to implement the digitized curriculum effort, however turnover in leadership and responses to other school improvement efforts being conducted simultaneously impeded the progress of the district to focus on cultural improvements. Thus, the digitized curriculum effort to increase student engagement and achievement ultimately failed, as the improvement effort did not take into account necessary cultural components.

\section{Lack of Engagement}

The intentions of the Yellow Pine district administration were to use the SIG funding to digitize the curriculum and build the capacity of teachers to provide increased student engagement and achievement through the use of technology that would support turnaround school efforts. However, the unilateral decision of a past superintendent to digitize the curriculum and use a one-to-one tablet approach to improve classroom instruction hampered the school turnaround effort. As a result, neither the tribal community, teachers, nor students were provided any opportunity to have input on the improvement effort. The poor communication decision of this district leader led to a domino of effects on the Yellow Pine School District, including rushed decision-making, little buy-in among parents, students and teachers, and a lack of implementation fidelity among teachers and administrators, all of which point to a lack of engagement among Yellow Pine stakeholders.

Community engagement. In general, participants commented on the overall confusion of the one-to-one tablet initiative, stating that the process was rushed and poorly communicated to stakeholders throughout the district. Central office leaders reflected on the school improvement implementation process, commenting that the previous superintendent had spearheaded this effort before he abruptly left the district late in the spring, 
several months before the initiative was supposed to be fully implemented. The inherited reform, which was decided upon at the last part of the 2012-2013 school year to avoid SDOE corrective action, was done without the buy-in or input of the tribal community, or the school district employees in general. In reviewing collected district communication, the researchers could not find any recorded data or documentation in which a comprehensive needs assessment or community feedback sessions had been conducted. In the absence of this data, the only indication of stakeholders outside of the employment of the school district that was solicited is the statement of the former superintendent that several Yellow Pine school board members had expressed a desire for the school district to explore an increased use of technology in instruction. However, there were no records the Yellow Pine Board of Education made an official motion or charge to focus the allocations of resources to those ends.

The fact that many families refused to sign agreements that would hold them financially liable for loss or damage to the tablet devices further highlights the lack of community engagement. When the tablets were deployed for use, the intent was for students to use the technology in class and to take them home to complete work, however students could not complete the assigned work due to limited or no internet connectivity at their homes. If the district had completed a needs assessment, they could have potentially discovered that although Yellow Pine students had been exposed to similar devices because of the prevalence of smartphone cellular technology, the students would find it difficult to complete work as assigned due to remoteness and lack of internet connectivity. Due to the fact that many families saw the tablets as a potential financial burden if they became damaged or lost, some families refused to allow their students to bring the tablets home.

The long history of assimilation approaches to Native American education seemingly impacted the lack of engagement with the Yellow Pine community. Not only was there a lack of communication about the technology-based school reform effort from district leaders to the community of Yellow Pine, but there was also seemingly a lack of trust among the parents of Yellow Pine students. One central office administrator commented:

You have to remember where you are. Number one, the parents and grandparents were part of the boarding school era. There's a reticence to access school, so those tools allow discussions at home about what's happening at school. It's a piece in Native American culture. It's a piece that allows them to have a discussion with multi generations in their home.... If you wanted to [be abused] by priests and sisters, lose your culture, be beat, and frequently sexually abused, that's the history. That's the residual effect.

Now, we as White folks who have a leg up, we expect them to come readily to school, to access, "Hey, you're wonderful," when realistically we have to very slowly have intimate discussions and develop trust. Because it doesn't happen because... Native American people are the last to be included in this country. So there's no trust. Why would you trust somebody who's [abusing you]? Stole their land, took their stuff.

While this powerful quote highlights the need to foster better communication and engagement with tribal communities, it also acknowledges that education is still being done to Native American communities, as opposed to working collectively to identify areas of improvement that will lead to better education.

Teacher engagement. Another aspect of the lack of engagement regarding the reform effort was the absence of teacher involvement to help plan for and implement the digitization process. Teachers were told of the SIG funded effort late in the spring, giving them only two months to prepare for the massive undertaking of implementing the one-to-one initiative. Not only was time to implement the technology integration a concern for teachers, but perhaps an even bigger concern was the lack of input to determine which device would best serve their students. Teachers were told that when they returned in the fall, they would be teaching with a digitized curriculum and that the expectation was they would have 40 digitized lessons, called bundles, ready to teach the first day of school. There was no input from teachers regarding the type of tablet that would be adopted (or laptop for that matter), and little input was provided regarding the types of software that would be considered valuable to different content areas taught. One teacher reflected:

I think at the high school level, if we had a voice, I think we would have said that [a different tablet] or a laptop would have been more useful for our age group.... Well with the manipulatives that we can access on a laptop, uhm, for [my subject area], I can't access them on [this tablet] because it needs... another type of format.

It seems while the intention of the digitized curriculum improvement effort was to help improve student achievement, teachers were not given the opportunity to provide input or influence innovative 
thinking to promote change, mainly due to the lack of engagement between administrators and teachers of how to best utilize the technology in their rural context. Teachers also commented on a lack of time to internalize professional development on how to best construct digital lesson plans and provide high quality, pedagogically sound instruction. Additionally, teachers felt that administrators were unable to help provide instructional leadership with the initiative, mainly because of additional improvement efforts that were conflicting and demanded greater attention. Another teacher commented.

The administrators aren't in the classrooms to see the problems that we're having. And when it comes time to try and talk about it, you know, they just kind of turn and... walk away type of thing. They don't want to hear about the problems.

These instructional problems included bandwidth constrictions at various locations in the building, software crashes due to ongoing updates, lack of internet access for their rural students at home, and abuse of technology (i.e. use of tablets to record physical altercations, inappropriate pictures and videos, etc.). Thus, many teachers commented the previous superintendent that was no longer working in the district imposed the digitization process on them and placed a complex demand on their small, rural school system.

Student engagement. Perhaps the most critical form of a lack of engagement with stakeholders of the Yellow Pine community were the students who did not see the use of the tablet technology as a learning tool. Many administrators and teachers commented on the initial interest of the students during the first month or two of school, but by the end of October of the school year the novelty had worn off. Teachers commented that many students were losing their tablets or leaving them throughout the school buildings, when the intention was for students to take the tablets home and use them as part of their learning. A variety of issues led to this outlook, including the district having to respond to administrative issues of students using the cameras inappropriately, blocking websites that were not considered educational, and in general, helping students perceive the technology as a learning tool rather than a device to play games or browse the internet. One participant commented on the difficulty in trying to change the mindset of students on how the technology might be used.

We need some self-efficacy with our students. We need them to be engaging, that they will try. I don't know how to - that's hard to build, the,
"You can do it. Let's do this. It's on there for you....We've talked about this, now it's your turn to do something with it."

Likely due to the extremely rushed timeframe to bring this reform effort into full implementation, the researchers could not find any district documentation that took into account student perspectives, needs, or feedback. Similarly to the lack of input provided from parents and teachers, the students of Yellow Pine were not provide an opportunity to influence what type of technology was adopted. Thus, while teachers tried to engage students to use the technology, there was a lack of focus on the need to provide engaging instruction based on the perspectives of students. One teacher reflected: Yeah, and this the point I'm getting to. I think I've used this in one of our [book studies] - the Hattie [book] - the top people writing all these books in the world. They got up there and the guy - he was really impressive - pulled up a ballpoint pen from the '50s. He held it up to all of us. "This was technology in the 50s." Right? "This [tablet] is technology in the century, 2000, okay? It's only a tool. How do you use that tool to make it engaging?” And it really struck me. It really did. And it isn't the tool that's it for these kids. I mean, most of our kids like to play games on them. I think if we could have an application of games where it applied to [one content area or another], if I could find those apps, which people are using, right? And maybe do that, maybe that would work, that interactive type thing. I don't know. The overreliance on technology improvement efforts within this study, coupled with the fact that the largely White teaching staff did not consider implementing any culturally responsive teaching strategies beyond the mandatory Native American language and history classes, created an imbalance of targeting technical aspects with no cultural considerations. By the spring of the 2013-2014 school year, students had lost such interest in the use of the tablets that Yellow Pine High School reverted to a daily check-out system in order to prevent further loss and damage to the $\$ 1,350,000$ project, of which $\$ 850,000$ was spent on tablets and software. Before the end of the school year, some participants estimated that $25-35 \%$ of tablets had been damaged or destroyed.

\section{Discussion}

The general intent of this study was to contribute to the peer-reviewed literature regarding implementation of school turnaround efforts, particularly those in a rural community and in a 
Native American context. Findings suggest the importance of engaging a community in a turnaround process, and providing a balance between technical and cultural improvement efforts (Mette, 2013; 2014). Additionally, there is a continued need to examine how SIG funded efforts can be improved upon to better develop the capacity of traditionally underperforming rural schools to increase student achievement (Educational Resource Strategies, 2012), and not simply assume the increased use of technology to drive school improvement efforts will lead to greater student achievement (Herrmann et al., 2014).

Within the Yellow Pine School District, administrators missed an important opportunity to engage the Native American tribal community, as well as with the teachers and the students of Yellow Pine, to plan for and promote the digitized curriculum school reform improvement effort. Rather than repositioning itself as a hub for the rural community to share knowledge and instill cultural values (Howley et al., 2012), the it imposed its own organizational beliefs about what type of education is considered 'right' or 'correct' (Shumaker, 2007), isolated the Native American community it is intended to serve, and failed to engage the tribal community in the decision to partake in a digitized curriculum school improvement effort. Instead, the school district could have relied on the social capital of community members, students, and teachers to help highlight how the one-to-one initiative could be sustainably implemented and how the program would benefit the students of Yellow Pine (Donovan \& Green, 2010; Li, 2010; Yatsko et al., 2015). As a result there was a lack of engagement with the tribal community regarding how the use of technology could serve as means to promote Native American values, culture, identity, community and education (Charley, 2013; Huffman, 2011; Richardson \& McLeod, 2011), as well as use of technology to support change (Anthony, 2012).

Teachers also perceived the effort as an imposed school sanction that was burdensome and complex (Preston et al., 2013), and the fact that the teachers were not involved in the school improvement decision suggests that district officials viewed the Yellow Pine teachers as professionally resistant to technical change (Burton, Brown, \& Johnson, 2013). Additionally, students were not involved in the decision-making process either, particularly how technology might be used to further their own understanding of Native American education or cultural identity (Fletcher, 2008; Tharp, 2006). Rather than working with its rural stakeholders to help translate a vision into action (Wood et al., 2013), the Yellow Pine School District imposed a one-size-fits-all reform effort that did not take into account how technology might be used to teach tribal languages, history, or other aspects of Native American culture (Noori, 2011). Thus, after several months of using the digitized curriculum, teachers' efforts to use the digitized curriculum faded, students lost interest in the novelty of the instruction, and overall the district displayed an apathetic attitude towards the improvement effort.

By focusing almost exclusively on technical issues of turnaround, as opposed to targeting often crucial components necessary to improve culture within underperforming schools, these types of reform efforts highlight the fallacy of SIG funded improvement efforts that are purported to lead to increased student achievement (Renée \& Trujillo, 2014). From a critical perspective, the hyper focus to target student engagement with technology through the SIG funded digitized curriculum effort allowed for a White state system to influence a school district of Native American students to act more 'White' and encourage an assimilation approach to education (Roppolo \& Crow, 2007). Rather than taking the time to plan for how technology might help deconstruct a Euroamerican approach to education (Locke, 2004; Wexler, 2006), this technology-driven, top-down government initiative failed to support the very people it was intending to serve. As a result, the Yellow Pine tribe has not benefited from the $\$ 1,350,000$ invested in the school system, money that could have been spent differently to support culturally proficient education, improve parent engagement, further Native American language offerings, and support programs that could support the development of a greater number of Native American teachers (Demmert, McCardle, MeleMcCarthy, \& Leos, 2006).

\section{Conclusions}

Turnaround school efforts are possible, even plausible, with the right contextual support. However, given the case highlighted in Yellow Pine, sustainable school turnaround efforts are not likely to occur without considering the cultural and historical contexts surrounding a community. If the U.S. federal government wants to help historically disenfranchised rural communities such as Yellow Pine improve their education systems, there must be an acknowledgement of the need to provide input from community leaders, and consider cultural identities, to prevent further assimilation of indigenous peoples (Snyder, Williams, \& Peterson, 2003). While not generalizable to a larger population, this study might serve as a bellwether for the federal government that simply providing 
financial support through SIG funded efforts, and ignoring cultural considerations, might not improve student outcomes in historically disenfranchised communities - it can certainly serve as an example of the failure of national standards-based reform efforts that provide little or no space for culturally-based instruction (Beaulieu, 2011). The findings from this study also reinforce the reality that life on a Native American reservation reflects high levels of poverty and low levels of education (Locke, 2004).

To alter the current paradigm of how SIG efforts might provide greater impact to promote longterm change among minority groups, the authors believe there must be opportunity for students in these communities to examine race, culture, identity, can community (Noel, 2002), historically and in present terms. Additionally, rather than invest $\$ 1,350,000$ in a program that is no longer in use, the authors also believe there is an opportunity to alternatively invest SIG funds in human capital to build capacity among school systems and with community leaders to better the social and economic conditions of the students and families they serve. Within Yellow Pine, the opportunity to invest in the people of the tribe, specifically in developing Native American teachers and providing opportunities on the Yellow Pine Reservation to support economic opportunities (i.e. using SIG funds in an alternative manner to develop economic franchises that might improve the quality of living) could be more impactful rather than working through a White, state system that does not acknowledge the importance of culture and history when attempting to rapidly improve a school.

Future research can, and should, inform our understanding of ongoing rural school turnaround efforts and suggestions for improved policy. One direction for additional research would be to study other Native American communities whose school districts are implementing school turnaround efforts to see if there are alternate approaches to supporting other historically disenfranchised groups. Ongoing studies on how, and to what extent, other school districts that support a large percentage of Native American students successfully increase culturally proficient instruction might help researchers, practitioners, and policy-makers bridge the gap between theory and practice to better support school improvement in traditionally failing schools. Moreover, conducting a longitudinal, mixed-methods study of various rural turnaround schools throughout the country, and the impact turnaround school policy has on improving achievement and community involvement, would be crucial in evaluating the overall effectiveness of turnaround school policy in general.

\section{References}

Anthony, A. B. (2012). Activity theory as a framework for investigating district-classroom system interactions and their influences on technology integration. Journal of Research on Technology in Education, 44(4), 335-356.

Beaulieu, D. L. (2011). The education policy work of William Demmert, Jr. Journal of American Indian Education, 50(1), 7-31.

Blackley, S., \& Walker, R. (2015). One-to-one laptop programs: Is transforming occurring in mathematics teaching? Issues in Educational Research, 25(2), 99-117.

Burton, M., Brown, K., \& Johnson, A. (2013). Storylines about rural teachers in the United States: A narrative analysis of the literature. Journal of Research in Rural Education, 28(12).

Charley, E. (2013). Review of the book American Indian/First Nations schooling: From the colonial period to the present, by C. L. Glenn. Journal of Research in Rural Education, 28(1), 1-5.

Creswell, J. W. (2013). Qualitative inquiry and research design: Choosing among five approaches ( $3^{\text {rd }}$ ed.). Thousand Oaks, CA: Sage.

Demmert, W., McCardle, P., Mele-McCarthy, J., \& Leos, K. (2006). Preparing Native American children for academic success: A blueprint for research. Journal of American Indian Education, 45(3), 92-106.

Dexter, S. (2011). School technology leadership: Artifacts in systems of practice. Journal of School Leadership, 21(2), 166-189.

Donovan, L, \& Green, T. (2010). One-to-one computing in teacher education: Faculty concerns and implications for teacher educators. Journal of Digital Learning in Teacher Education, 26(4), 140-148.

Doolittle, G., \& Browne, E. G. (2011). Who moved my curriculum? Leadership preparation programs and the core technology of schools. Journal of School Leadership, 21(2), 293-318.

Duke, D. (2012). Tinkering and turnarounds: Understanding the contemporary campaign to improve low-performing schools. Journal of Education for Students Placed at Risk, 17(1-2), 9-24. 
Education Resource Strategies (2012). Investing for sustainable turnaround: Sustaining school turnaround at scale. Retrieved from http://files.eric.ed.gov/fulltext/ED541227.pdf.

Fletcher, M. L. M. (2008). American Indian education: Courternarratives in racism, struggle, and the law. New York: Routledge.

Forner, M., Bierlein-Palmer, L., \& Reeves, P. (2012). Leadership practices of effective rural superintendents: Connections to Waters and Marzano's leadership correlates. Journal of Research in Rural Education, 27(8), 1-13.

Freeman, C., \& Fox, M. (2005). Status and trends in the education of American Indians and Alaska Natives (NCES 2005-108). Washington, DC: U.S. Department of Education, National Center for Education Statistics.

Gorski, P. C., \& Zenkov, K. (2014). Introduction. In P. C. Gorski and K. Zenkov (Eds.), Big lies of school reform: Finding better solutions for the future of public education (pp. 1-4). New York: Routledge.

Herrmann, M., Dragoset, L., \& James-Burdumy, C. (2014). Are low-performing schools adopting practices promoted by School Improvement Grants? National Center for Education Evaluation and Regional Assistance (NCEE 2015-4001). Washington, DC.

Howard, S. K., \& Rennie, E. (2013). Free for all: A case study examining implementation factors of one-to-one device programs. Computers in the Schools, 30(4), 359-377.

Howley, A., Howley, M., Hendrickson, K., Belcher, J., \& Howley, C. (2012). Stretching to survive: District autonomy in an age of dwindling resources. Journal of Research in Rural Education, 27(3), 1-18.

Howley, A., Wood, L, \& Hough, B. (2011). Rural elementary school teachers' technology integration. Journal of Research in Rural Education, 26(9), 1-13.

Huffman, T. E. (2011). Plans to live on a reservation following college among American Indian students: An examination of transculturation theory. Journal of Research in Rural Education, 26(3), 1-13.

James-Burdumy, C. (2015). Usage of policies and practices promoted by Race to the Top and School Improvement Grants: Executive Summary. National Center for Education Evaluation and Regional Assistance (NCEE 2015-4017). Washington, DC.

Johnson, J., \& Howley, C. B. (2015). Contemporary federal education policy and rural schools: A critical policy analysis. Peabody Journal of Education, 90(2), 224-241.
Li, S. C. (2010). Social capital, empowerment and educational change: A scenario of permeation of one-to-one technology in school. Journal of Computer Assisted Learning, 26(4), 284-295.

Locke, S. (2004). Reflections of Native American teacher education on Bear Ridge. The Rural Educator, 26(1), 15-23.

Maninger, R. M., \& Holden, M. E. (2009). Put the textbooks away: Preparation and support for a middle school one-to-one laptop initiative. American Secondary Education, 38(1), 5-33.

McLeod, S., Bathon, J. M., \& Richardson, J. W. (2011). Studies of technology tool usage are not enough: A response to the articles in this special issue. Journal of Research on Leadership Education, 6(5), 288-297.

McLeod, S., \& Richardson, J. W. (2011). The dearth of technology leadership coverage. Journal of School Leadership, 21(2), 216-240.

Mette, I. M. (2013). Turnaround as reform: Opportunity for meaningful change or neoliberal posturing? Interchange, 43(4), 317342.

Mette, I. M. (2014). Turnaround reform efforts in a rural context: How community and culture impart change. The Rural Educator, 35(3) 1221.

Miles, M. B., Huberman, A. M., \& Saldaña, J. (2014). Qualitative data analysis: A methods sourcebook ( $3^{\text {rd }}$ ed.). Thousand Oaks, CA: Sage.

Mortensen, C. (2011). Mission possible: Keys to oneto-one success. Learning \& Leading with Technology, 29(1), 16-21.

Noel, J. (2002). Education toward cultural shame: A century of Native American education. Educational Foundations, 16(1), 19-32.

Noori, M. (2011). Waasechibiiwaabikoonsing Nd'anami'aami, "Praying through a wired window": Using technology to teach Anishinaabemowin. Studies in American Indian Literatures, 23(2), 1-23.

Preston, J. P., Jakubiec, B. A. E., \& Kooymans, R. (2013). Common challenges faced by rural principals: A review of the literature. The Rural Educator, 35(1), 1-12.

Redding, S., Dunn, L, \& McCauley, C. (2015). School Improvement Grants: Guidance and tools for the 2015 amended regulations: Maximizing the optional planning/preimplementation year. Center on School Turnaround. San Francisco: WestEd.

Renée, M., \& Trujillo, T. (2014). The trouble with federal turnaround policies and their impact on low-scoring schools. In P. C. Gorski and K. Zenkov (Eds.), Big lies of school reform: 
Finding better solutions for the future of public education (pp. 153-168). New York: Routledge.

Richardson, J. W., \& McLeod, S. (2011). Technology leadership in Native American schools. Journal of Research in Rural Education, 26(7), 1-14.

Rosen, Y., \& Beck-Hill, D. (2012). Intertwining digital content and a one-to-one laptop environment in teaching and learning: Lessons for the Time to Know Program. Journal of Research on Technology in Education, 44(3), 225-241.

Rosenberg, L, Christianson, M. D., \& Angus, M. H. (2015). Improvement efforts in rural schools: Experiences of nine schools receiving School Improvement Grants. Peabody Journal of Education, 90(2), 194-210.

Rosenberg, L., Christianson, M. D., Angus, M. H., \& Rosenthal, E. (2014). A focused look at rural schools receiving School Improvement Grants. Jessup, MD: National Center for Education Evaluation and Regional Assistance.

Rubin, H. J., \& Rubin, I. S. (2012). Qualitative interviewing: The art of hearing data ( $3^{\text {rd }}$ ed.). Thousand Oaks, CA: Sage.

Saldaña, J. (2013). The coding manual for qualitative researchers ( $2^{\text {nd }}$ ed.). Thousand Oaks, CA: Sage.

Schrum, L, Galizio, L. M., \& Ledesma, P. (2011). Educational leadership and technology integration: An investigation into preparation, experiences, and roles. Journal of School Leadership, 21(2), 241-261.

Scott, C., \& McMurrer, J. (2015). Mission impossible? What states with large percentages of rural schools tell us about federal School Improvement Grants. Peabody Journal of Education, 90(2), 211-223.

Shumaker, C. (2007). Out of the classroom and into the canyons: An American Indian travel course in theory and practice. Studies in American Indian Literatures, 19(1), 32-48.

Snyder, R., Williams, D., \& Peterson, G. (2003). Culture loss and sense of place in resource valuation: Economics, anthropology and indigenous cultures. In S. Jentoft, H. Minde, and R. Nilsen (Eds.), Indigenous peoples: Resource management and global rights (pp. 107-124). Delft, The Netherlands: Eburon Academic Publishers.

Stein, L., Stein, J., \& Stein, A. (2013). Education disrupted: Strategies for saving our failing schools. Lanham, MD: Rowman \& Littlefield.

Tanenbaum, C., Boyle, A., Graczewski, A., JamesBurdumy, C., Dragoset, S., \& Kallgren, K. (2015). State capacity to support school turnaround. National Center for Education Evaluation and Regional Assistance (NCEE 2015-4012). Washington, DC.

Tharp, R. G. (2006). Four hundred years of evidence: Culture, pedagogy, and Native America. Journal of American Indian Education, 45(2), 6-25.

Treuer, D. (2012). Rez life: An Indian's journey through reservation life. New York: Atlantic Monthly Press.

US Department of Education (US DOE, 2011). An overview of school turnaround. Retrieved from http://www2.ed.gov/programs/sif/sigoverv iewppt.pdf.

US Department of Education (US DOE, 2013). Applicant information. Retrieved from http://www2.ed.gov/programs/sif/applicant.htm.

US Department of Education (US DOE, 2010). ESEA Blueprint for Reform. Washington, DC.

Warschauer, M., Zheng, B., Niiya, M., Cotton, S., \& Farkas, G. (2014). Balancing the one-to-one equation: Equity and access in three laptop programs. Equity \& Excellence in Education, 47(1), 46-62.

Wood, J. N., Finch, K., \& Mirecki, R. M. (2013). If we get you, how can we keep you? Problems with recruiting and retaining rural administrators. The Rural Educator, 34(2).

Yatsko, S., Lake, R., Bowen, M., \& Nelson, E. C. (2015). Federal School Improvement Grants (SIGs): How capacity and local conditions matter. Peabody Journal of Education, 90(1), 27-52.

\section{About the authors:}

Ian Mette is an Assistant Professor in Educational Leadership at the University of Maine. His areas of research and teaching interests include school reform, teacher supervision, and the merging of the two to drive real, meaningful improvement of instruction. Correspondence regarding this article can be directed to ian.mette@maine.edu.

Jason Stanoch is a practicing school administrator and research practitioner in Minnesota. He is also a recent Ed.D. graduate from the University of Missouri. His areas of research and teaching interests include teacher supervision, teacher preparation, and school improvement efforts that connect theory to practice in meaningful ways that lead to increased student achievement. Correspondence regarding this article can be directed to jasonstanoch6@gmail.com. 